\title{
Analysis on Path for Energy Companies to Improve Their Crisis and Emergency Management Capabilities
}

\author{
Caihua Zhang ${ }^{1}$, Xiling $\mathrm{Wu}^{1 *}$, Tingran Zhang ${ }^{1}$ \\ ${ }^{1}$ School of Economics and Trade, Xinhua College of Sun Yat-sen University (Dongguan), Guangzhou, 510520, China
}

\begin{abstract}
Energy is a national strategic resource affecting national welfare and people's livelihood, which also determines the social attributes of the energy industry. Thai it, its development affects both the economic development level and social security and stability. This paper will discuss how to effectively improve the crisis and emergency management capabilities of energy companies. First, it analyzes how energy companies build the modern integrated emergency response platform by adopting advanced information technologies; based on which, it will analyze the path for energy companies to improve their crisis and emergency management capabilities from company and government perspectives.
\end{abstract}

\section{Introduction}

Affected by the COVID-19, the crisis and emergency response capabilities of energy companies have been given a lot of attention. Because their capabilities of responding to emergencies can directly reflect the perfection level of the entire social energy governance system. To this end, it has become a key issue how to efficiently construct and improve energy companies' crisis and emergency management system, so as to effectively improve their crisis and emergency management capabilities.

\section{Construction of Energy Companies' Modern Integrated Emergency Response Platform}

During the COVID-19 period, most of energy companies responded quickly, including formulating higherstandard epidemic prevention and control measures, and investigating and checking in a timely and full-range manner, which has provided health and safety guarantees for practitioners in energy industry while providing manpower guarantee for the follow-up resumption of work and production. However, their emergency management system still shows flaws, requiring further improvement. Under such circumstances, based on the current emergency management system, energy companies are required to build and improve the modern integrated emergence response platform on the basis of big data analysis and Internet of Things technology taking full use of modern information measures, so as to develop the emergency management system into a more intelligent and efficient direction.

As shown in Figure 1, the modern energy emergency response platform is supported by modern information and communication technology. It is a public emergency response protection technology system combining both software and hardware, which mainly including early warning monitoring, various emergencies response plan mechanism, intelligent alarm system, command and control system, emergency support system, and real-time monitoring system. The platform serves as the carrier for implementing emergency plans, and realizing the emergency command decisions. Emergency management is based on the construction of an emergency platform, which is of great significance for establishing and improving the emergency mechanism, preventing and responding to public emergencies, and reducing losses caused by disasters.

\subsection{Early warning and monitoring}

The early warning and monitoring are mainly adopted for common emergencies arising from daily operation of energy companies, including fire source detection, weather warning, and traffic warning. Besides, personnel health detection system is also added affected by the severity and continuity of the current global pandemic.

\subsection{Intelligent alarm}

The system is designed to realize rapid alarm linkage through various paths after an emergency event breaks out. Except for manually initiating the emergency alarm device, the system is also equipped with the Internet of Things detection alarm system and the video monitoring linkage alarm system.

\footnotetext{
* Corresponding author: etwx157@xhsysu.edu.cn
} 


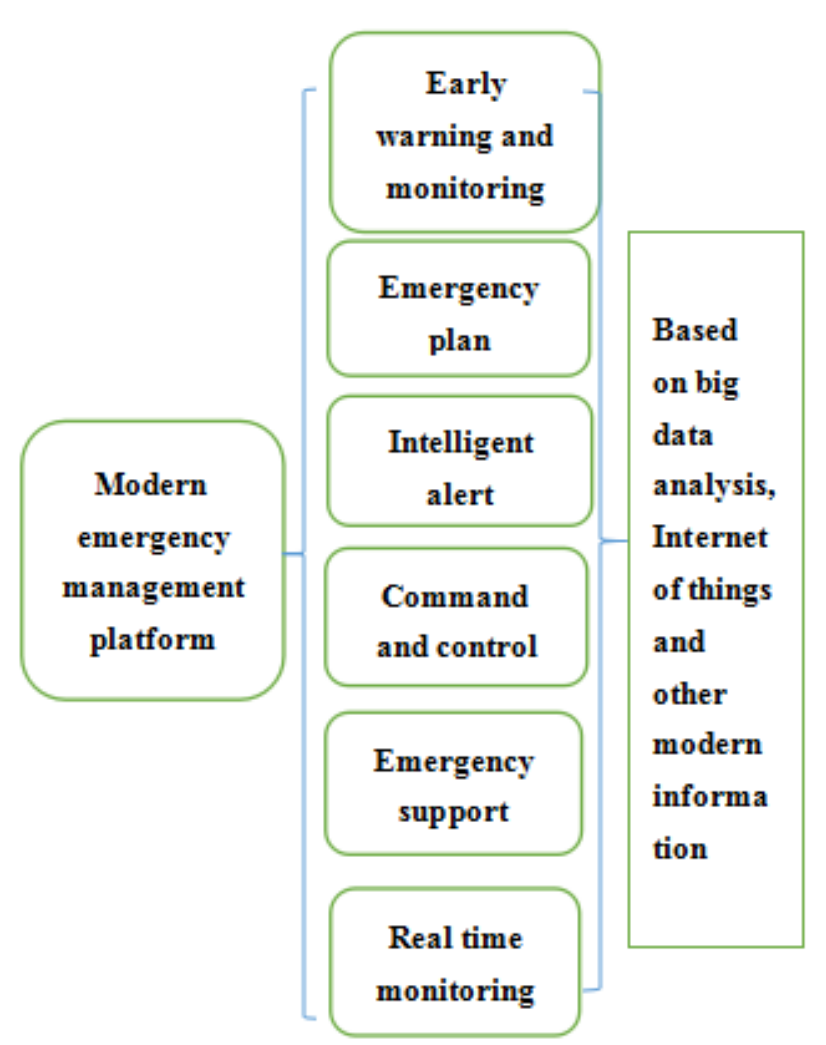

Fig. 1. Modern emergency management platform for energy enterprises.

\subsection{Command and control}

Once the emergency alarm is sounded, the command and control system provides the commander with intelligent decision-making reference and targeted information network in accordance with the actual situation, which enables the manager respond quickly and mobilize the emergency management personnel to intervene the crisis.

\subsection{Emergency support}

Energy companies should be equipped with rich emergency supports at any time, including emergency personnel support, emergency material support, and emergency equipment support, which serve as the fundamental supports for companies to carry out emergency management.

\subsection{Real-time monitoring}

The system is mainly adopt to monitor and control the situation after the emergency event breaks, during the emergency treatment, and after the event. The big data analysis makes it possible to accurately master the emergency response process and effects, so as to make decisions and adjust in a timely manner. Moreover, the system can carry out dynamic and visual internal communication of the emergency management system, so as to feedback questions or opinions in real time.

\subsection{Contingency plan}

The contingency plan is also named as emergency plan, which constitutes an important part of the emergency management system of energy enterprises, providing support for realizing efficient emergency management. The emergency plans of enterprises are commonly diversified and made in advance to deal with all kinds of emergencies that may occur, which include the predictions and impacts of all incidents, as well as the construction of emergency management mechanisms. Please check Figure 2 for detailed information:

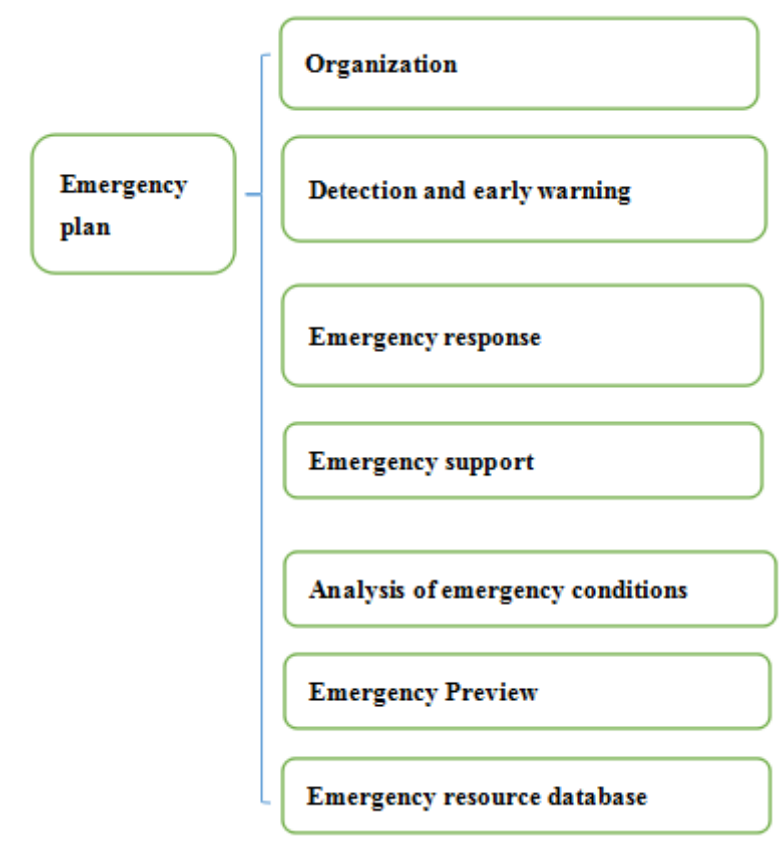

Fig. 2. Components of emergency plan.

The emergency plan refers to a very specific emergency management plan, which includes the entire emergency management link before, during and after the emergency breaks out. Moreover, the emergency plan will also specify the composition and division of labor of the emergency management team members, and also include the accountability mechanisms under normal circumstances. Since the traditional emergency plans have flaws of inconvenience for reviewing or looking for relevant information needed rapidly for generally being stored in folders or computers in the form of corporate files, enterprises should establish the digital plan system to present each module in the system separately in accordance with categories, so as to realize convenient review and learning at ordinary times, as well as obtain relevant information and make effective decisions under emergency situation.

\section{Analysis on paths for energy companies to improve their crisis and emergency management capabilities}

Once energy companies build their internal emergency management system, they should also improve their crisis and emergency management capabilities through 
diverse paths in accordance with their own industry characteristics and external influences. Moreover, the government can also promote the constant improvement for emergency management system of the energy industry through policy interventions, so as to escort energy companies.

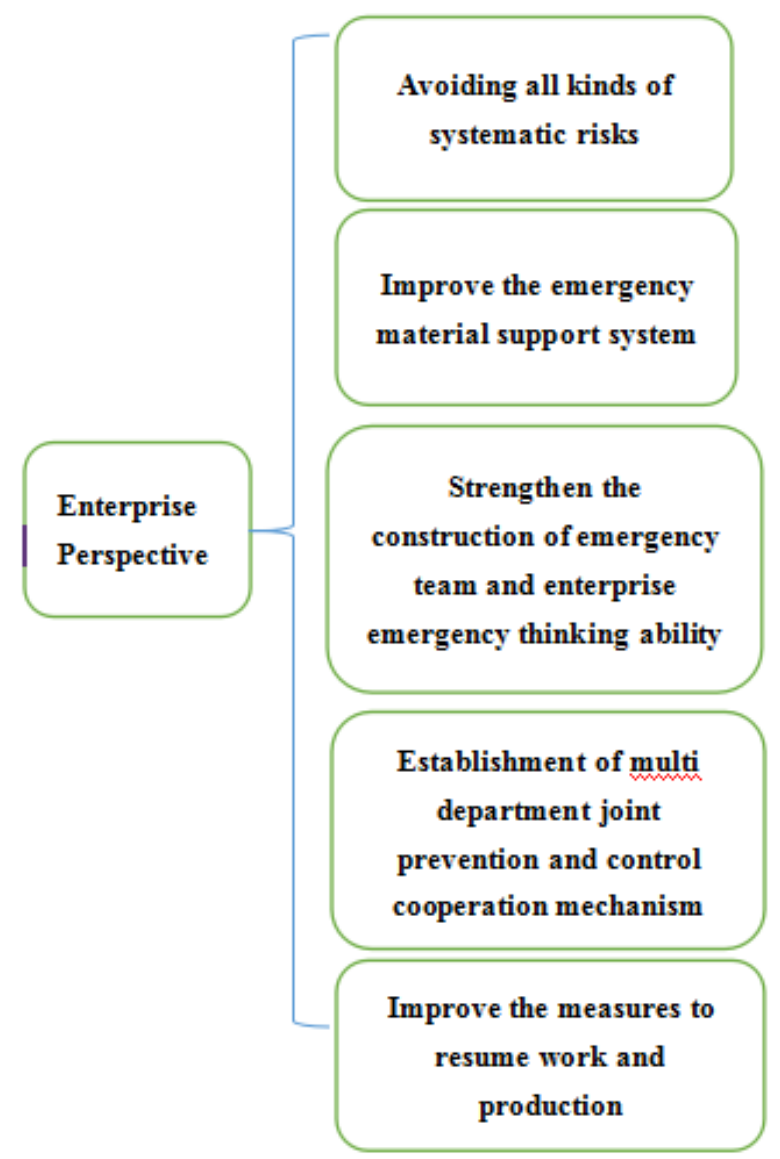

Fig. 3. Ways for enterprises to improve their emergency management ability.

\subsection{Paying attention to industry development trends to avoid systemic risks in a timely manner}

As the division of labor of the energy industry chain refines constantly, and modern network technology develops, the main body of energy enterprises is developing towards a diversified and complex direction. So that a multi-dimensional interconnected organic system is formed for its constantly updated correlation. Although such a feature favors the rapid development of the energy industry, the probability for systemic risks increases when a certain network node is affected by an emergency event. Under such circumstances, energy companies are required to be equipped with the ability to predict the linkage risks of the energy system, so as to formulate the integrated and specific emergency plans in advance, actively explore and construct the emergency crisis response dynamic mechanisms to achieve the optimal allocation of emergency resources.

\subsection{Improving the emergency material support system and ensuring the supply of emergency reserve resources}

As a basic industry supporting the production of companies and the lives of all people, the emergency reserve resources condition of energy companies affects the stability of the entire society. Especially in the current fighting against the pandemic, energy supply is particularly important. Therefore, energy companies shall strengthen their emergency material reserves and emergency team construction, improve their internal resource allocation function designs, build regional decentralized warehouse for storing energy materials, open up multiple energy distribution channels, maintain smooth transportation channels, and constantly improve the emergency materials support system, so as to improve the materials resources and organizational efficiency under emergency conditions.

\subsection{Strengthening the construction of emergency team and companies' emergency thinking abilities}

First, energy companies should matter the construction of emergency management teams to establish a company emergency expert database, so as to carry out integrated crisis drills on a regular basis, promote the construction of professional teams and daily crisis management, and improve team emergency response capabilities; moreover, energy companies are required to strengthen the construction of emergency management related databases, carry out the emergency knowledge and skills training for all employees on a regular basis, so as to improve their overall emergency management awareness and capabilities.

\subsection{Strengthening companies' risk management and establishing a joint prevention and control coordination mechanism among departments}

Facing all kinds of emergency events, enterprises are required to develop strong emergency response in dealing with certain events. Meanwhile some events also require enterprises to be equipped with strong risk control capabilities before and during the event. For example, compared with extreme weather disasters, it is more necessary for companies to establish a corresponding risk management and control system affected by the current pandemic. Moreover, interdepartment coordination is required for the risk management and control. To this end, energy companies and government emergency management agencies, as well as professional institutes such as meteorological, medical, hydrological institutions have to establish cooperation and coordination mechanisms for information sharing, joint prevention and control, so as to continuously improve their emergency response capabilities. 


\subsection{Adhering to the "people-oriented" principle and improving measures for resuming work and production}

In case of circumstances, companies are required to put the safety of their employees first. Therefore, such a principle should be abided during the entire process of corporate emergency management and subsequent resumption of works and productions. In addition, it shall properly arrange employees affected, and protect on-the-job employees, so as to save human capital for the resuming work and production. For example, in the later stages of the pandemic, companies should strengthen protective measures after resuming work and production, especially paying attention to the mental and physical health of grassroots front-line employees during the pandemic prevention and control period.

\subsection{Government level}

First, the government is required to provide policy facilitation for the joint prevention and control between departments, and lead to build an interconnection platform to promote the efficient communication among all departments. Second, the energy authority shall decentralize and assign powers to the front-line staff to a certain extent, so that when companies can respond quickly to reduce losses in case of crisis. Moreover, relevant management departments shall perfect the information disclosure management mechanism. Since higher requirements are proposed for information spread, disclosure, feedback speed and efficiency by the particularity and complexity of the energy industry, the management department shall adopt $\mathrm{s}$ flat and extensive information reporting and feedback channel. At the same time, it shall also establish a rapid disclosure system of accurate information under emergency situation, so as to give a full play to the triggering effect played by the information on market mechanisms, and enhance the initiative of energy emergency works.

\section{4 conclusion}

The novel coronavirus pneumonia almost detected the basic necessities of life and risk management and control of all enterprises. The energy industry as a basic industry in the country is healthy and safe, which concerns the daily necessities of life and the sustainable production of many enterprises. It is also important to effectively improve the emergency management capability of energy enterprises. Through the analysis, energy enterprises can improve their own emergency management mechanism, broaden emergency management ideas and enhance emergency management ability by building a modern emergency platform, improving industry linkage risk prediction ability, and strengthening the construction of enterprise emergency management team.

\section{ACKNOWLEDGMENT}

This work was supported by Characteristic Key Discipline Project of Guangdong Province (Crisis and Emergency Management), Scientific research fund projects of Xinhua College of Sun Yat-sen University (2017QN004,2018ZDXKZZ03), "The COVID-19" epidemic prevention and control research project (2020YQYJ06).

\section{References}

1. Li Chao. Research on the construction of work safety emergency management system [D]. University of Defense Science and technology, 2016.

2. $\mathrm{Lu} \mathrm{Yu}$ et al. The impact of the epidemic will promote the improvement of energy safety production and emergency management $[\mathrm{J}]$. Power decision making and public opinion reference, 2020 (2).

3. Zhang Qian et al. How to improve the emergency crisis management ability of energy enterprises? [J] State Grid news, 2020 (3).

4. Li Jiangtao. Energy emergency management: international practice and Chinese exploration [M]. Economic Science Press, 2011.

5. Zhang Heng. Introduction to improving the emergency management ability of petroleum enterprises [J]. Standards and quality of China Petroleum and chemical industry. 2017 (09).

6. Lu pin.Design of environmental safety emergency monitoring and early warning management system for petrochemical enterprises [J].Petrochemical Automation. 2020 (03).

7. Tan Bangjian. Analysis on the construction of safety production management system of power supply enterprises [J]. Low carbon world. 2018 (10).

8. Wei Ji Gang, Cui Lixin. Construction of emergency management system from New Coronavirus's prevention and control [J]. Technology China. 2020 (03).

9. Jian LI. Research on Emergency Management Information System for Power Supply Enterprises [J]. Agricultural Science \& Technology and Equipment. 2013 (06). 